\title{
Ecological Momentary Assessment of Depression in People With Advanced Dementia: Longitudinal Pilot Study
}

Iulia Niculescu ${ }^{1,2}$, MSc; Hannah Quirt ${ }^{2}, \mathrm{RPN}$; Twinkle Arora ${ }^{2}, \mathrm{MA}$; Terry Borsook ${ }^{2}, \mathrm{PhD}$; Robin Green ${ }^{1,2,3}, \mathrm{PhD}$; Brett Ford ${ }^{4}$, PhD; Andrea Iaboni ${ }^{1,2,3}, \mathrm{MD}$, DPhil

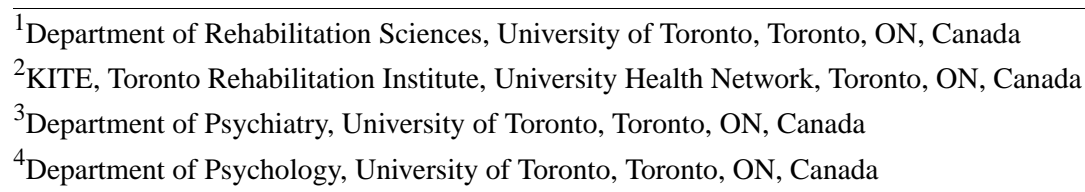

Corresponding Author:

Andrea Iaboni, MD, DPhil

KITE

Toronto Rehabilitation Institute

University Health Network

550 University Avenue

Toronto, ON, M5G 2A2

Canada

Phone: 1 (416) 5973422 ext 3027

Email: andrea.iaboni@uhn.ca

\section{Abstract}

Background: Barriers to assessing depression in advanced dementia include the presence of informant and patient recall biases. Ecological momentary assessment provides an improved approach for mood assessment by collecting observations in intervals throughout the day, decreasing recall bias, and increasing ecological validity.

Objective: This study aims to evaluate the feasibility, reliability, and validity of the modified 4-item Cornell Scale for Depression in Dementia for Momentary Assessment (mCSDD4-MA) tool to assess depression in patients with advanced dementia.

Methods: A intensive longitudinal pilot study design was used. A total of 12 participants with advanced dementia were enrolled from an inpatient psychogeriatric unit. Participants were assessed using clinical depression assessments at admission and discharge. Research staff recorded observations four times a day for 6 weeks on phones with access to the mCSDD4-MA tool. Descriptive data related to feasibility were reported (ie, completion rates). Statistical models were used to examine the interrater reliability and construct and predictive validity of the data.

Results: Overall, 1923 observations were completed, representing 55.06\% (1923/3496) of all rating opportunities with 2 raters and $66.01 \%(1923 / 2913)$ with at least one rater. Moderate interrater reliability was demonstrated for all items, except for lack of interest. Moderate correlations were observed between observers and patient-reported outcomes, where observers reported fewer symptoms relative to participants' self-reports. Several items were associated with and able to predict depression.

Conclusions: The mCSDD4-MA tool was feasible to use, and most items in the tool showed moderate reliability and validity for assessing depression in dementia. Repeated and real-time depression assessment in advanced dementia holds promise for the identification of clinical depression and depressive symptoms.

(JMIR Aging 2021;4(3):e29021) doi: 10.2196/29021

\section{KEYWORDS}

dementia; depression; ecological momentary assessment; tool performance 


\section{Introduction}

\section{Background}

\section{Dementia and Depression}

Dementia and depression are the most common psychiatric conditions in aging, and there is considerable overlap between them, with the prevalence of depression between $5 \%$ and $77 \%$ in people with dementia and between $7 \%$ and $54 \%$ in people at the advanced stage of dementia [1-3]. This wide range demonstrates the challenge in identifying depression in individuals with dementia, including individuals with advanced dementia, a group frequently excluded from studies [3]. The overlap between symptoms of depression and symptoms of dementia (eg, concentration difficulties and apathy) can also confound the diagnosis of depression, making it difficult to assess [4,5]. Many clinical interviews and assessments for depression in dementia include both informant reports and self-reports, and informant reports can be affected by confounding depressive symptoms for symptoms of dementia, mood-congruent biases (eg, related to caregiver burden projected onto the person with dementia), and recall biases [6,7]. Self-reports of people with dementia are limited by memory impairment, poor insight, and language impairment [8-10]. Although validated criteria and tools exist, such as the 19-item Cornell Scale for Depression in Dementia-19 (CSDD-19) [4-11], there is an opportunity to improve the detection and assessment of depression in people with advanced dementia $[12,13]$. People with dementia and comorbid depression are at risk for negative outcomes, such as hastened cognitive decline and higher rates of morbidities and mortality $[14,15]$. Detecting depression where it might otherwise be missed provides an opportunity for greatly enhanced patient care in this vulnerable population.

\section{Ecological Momentary Assessment}

Novel data collection methodologies provide promising opportunities for improving the measurement of depression in people with dementia. Ecological momentary assessment (EMA) encompasses a range of longitudinal data collection methods that capture momentary symptoms repeatedly over time and are typically registered on mobile devices [9]. Real-time and repeated measurements of behaviors and emotions can provide valuable information related to an individual's dynamic internal state and fluctuations in the expression of symptoms. EMA helps to address various methodological limitations of conventional tools, such as reducing recall bias and enhancing the ecological validity of the data collected [9]. EMA studies in older adults have demonstrated its feasibility, enhanced precision of outcome measurement, and the ability to identify clinically significant depressive symptoms, although most studies exclude people with dementia and are typically self-reported [16-18]. Informant-rated EMA studies are less common than self-reported EMA studies but have been used in the population of people with dementia. For example, daily self-reports of emotional well-being in people with dementia have been compared with informant reports, and internal consistency was found between the two data sources [19]. The use of an observational affect scale was examined in individuals with dementia using EMA. The scale demonstrated excellent reliability among activity therapists as well as family members and nursing assistants and good validity [20]. EMA has thus been used to monitor daily life behaviors and well-being in people with dementia, and these studies have demonstrated the validity of informant ratings and the ability to capture individual differences over time [20-23]. However, no EMA depression screening tools have been developed for people with advanced dementia.

\section{Objective}

This study seeks to address these gaps in a pilot intensive longitudinal EMA study of people with advanced dementia in an inpatient psychogeriatric unit. The aim of this study is to evaluate the psychometric performance of an EMA tool for assessing depression in people with advanced dementia. The first objective is to test the preliminary feasibility outcomes of an observer-rated EMA tool by examining the completion rates and observations of participant acceptability. The second objective is to test the reliability of an observer-rated EMA tool in advanced dementia by examining the reliability of within-person changes and interrater reliability. The third objective is to explore the construct validity and ability of the tool to predict clinical depression and depressive symptoms in patients with advanced dementia. To address these objectives, we conducted a pilot intensive longitudinal study using a modified 4-item Cornell Scale for Depression in Dementia for Momentary Assessment (mCSDD4-MA) tool.

\section{Methods}

\section{Participants and Sample Size}

Participants were patients admitted to the Specialized Dementia Unit at the Toronto Rehabilitation Institute. For study inclusion, participants should be aged $\geq 65$ years and have a diagnosis of moderate-to-severe dementia based on a Mini-Mental State Examination [24] score of $<20$ [3]. Substitute decision makers provided informed consent, and participants were excluded if they showed signs of dissent to the study procedures, had a previous history of bipolar disorder or schizophrenia, were receiving palliative care, or were unable to understand and speak English (ie, required to self-report).

In keeping with previous pilot EMA studies [16,25,26], the sample comprised 12 participants. Recommendations for determining sample size in intensive longitudinal designs are based on the power of both the within- and between-person sample sizes [27,28]. Despite our smaller between-person sample size $(\mathrm{n}=12)$, the within-person sample size (ie, number of repeated observations) is important in detecting the reliability of the random effects and within-person variability and typically requires $>50$ observations per individual and $>1000$ observations in total [29-31]. With our study design, we aim to achieve a large number of observations well above this cutoff (ie, eight observations per day for 6 weeks, totaling approximately 336 observations per participant), providing sufficient power for our primary within-person analysis [32]. Our third objective, which involved a between-person analysis, was exploratory in nature and no sample size calculation was completed. 


\section{Design and Setting}

We used a pilot observational study design. Observers consisted of 4 trained research staff members. The study was set on the Specialized Dementia Unit at the Toronto Rehabilitation Institute, a psychogeriatric unit caring for people with behavioral and psychological symptoms of dementia. This study was approved by the research ethics board of the University Health Network (Coordinated Approval Process for Clinical Research ID: 19-5132).

\section{Measures}

\section{Participant Characterization}

At baseline, demographic data collected included sex, age, and dementia diagnosis. The Mini-Mental State Examination was completed by a research assistant to assess cognition [24].

\section{Outcome Variables \\ mCSDD4-MA Tool}

The mCSDD4-MA tool (Table 1 and Textbox 1) was used as the primary data collection tool. The tool measures depressive symptoms collected by observers, modified for the purposes of this study from the 4-item CSDD (CSDD-4) [13]. Modifications included changing the retrospective language in the CSDD-4 tool to refer to the present, as is necessary for momentary assessments. The final tool consisted of five observational items: sadness, anxiety, irritability, and lack of interest (ie, from the original tool). Negativity was added as it is common in other assessments, including the CSDD-19 tool, and has good specificity in distinguishing between individuals with and without depression in dementia (Table 1) $[1,11,33]$. In addition to the observational component, a patient-reported component was added, which was unique to the tool (Textbox 1). Patient-reported outcomes included sadness and anxiety as they were central symptoms of depression in older adults [34], were relatively simple concepts to communicate [35], and have shown to be discordant between informants and patients [7].

Table 1. Developed observational items in the modified 4-item Cornell Scale for Depression in Dementia for Momentary Assessment tool for people with advanced dementia.

\begin{tabular}{|c|c|c|c|}
\hline $\begin{array}{l}\text { Original CSDD } \\
\text { item }\end{array}$ & Question & mCSDD4-MA ${ }^{\mathrm{b}}$ tool items & Response scale \\
\hline Introduction & $\begin{array}{l}\text { I am going to ask you questions about how your relative has been } \\
\text { feeling during the past week. }\end{array}$ & $\begin{array}{l}\text { Looking at the person right } \\
\text { now and reflecting on their } \\
\text { mood today }\end{array}$ & $N / A^{c}$ \\
\hline Sadness & $\begin{array}{l}\text { Has your relative been feeling down, sad, or blue }{ }^{\mathrm{d}} \text { this past week? Has } \\
\text { she/he been crying at all? How many days out of the past week has she } \\
\text { been feeling like this? }\end{array}$ & $\begin{array}{l}\text { Does the person seem sad } \\
\text { or blue? }\end{array}$ & $\begin{array}{ll}\text { - } & \text { No sadness } \\
\text { - } & \text { Some sadness } \\
\text { - } & \text { A lot of sadness } \\
\text { - } & \text { Unable to evaluate }\end{array}$ \\
\hline Lack of interest & $\begin{array}{l}\text { If a pleasant event were to occur today (ie, going out with spouse, } \\
\text { friends, or seeing grandchildren), would your relative be able to enjoy } \\
\text { it fully, or might his/her mood get in the way of his/her interest in the } \\
\text { event or activity? Does your relative's mood affect any of the following: } \\
\text { his/her ability to enjoy activities that used to give him/her pleasure, } \\
\text { his/her surroundings, his/her feelings for family and friends? }\end{array}$ & $\begin{array}{l}\text { Is the person showing en- } \\
\text { joyment or pleasure in } \\
\text { what is going on around } \\
\text { them? }\end{array}$ & $\begin{array}{l}\text { - } \\
\text { - } \\
\text { - } \\
\text { Lome lack of interest } \\
\text { est } \\
\text { - } \quad \text { Unable to evaluate }\end{array}$ \\
\hline Anxiety & $\begin{array}{l}\text { Has your relative been feeling anxious this past week? Has she/he been } \\
\text { worrying about things she/he may not ordinarily worry about or rumi- } \\
\text { nating over things that may not be that important? Has your relative } \\
\text { had an anxious, tense, distressed, or apprehensive expression? }\end{array}$ & $\begin{array}{l}\text { Does the person seem anx- } \\
\text { ious or worried? }\end{array}$ & $\begin{array}{ll}- & \text { No anxiety } \\
\text { - } & \text { Some anxiety } \\
\text { - } & \text { A lot of anxiety } \\
\text { - } & \text { Unable to evaluate }\end{array}$ \\
\hline Irritability & $\begin{array}{l}\text { Has your relative felt short-tempered or easily annoyed this past week? } \\
\text { Has she/he been feeling irritable, impatient, or angry this week? }\end{array}$ & $\begin{array}{l}\text { Does the person seem irri- } \\
\text { table, annoyed, or angry? }\end{array}$ & $\begin{array}{ll}- & \text { No irritability } \\
\text { - } & \text { Some irritability } \\
\text { - } & \text { A lot of irritability } \\
\text { - } & \text { Unable to evaluate }\end{array}$ \\
\hline Negativity & $\begin{array}{l}\text { Has your relative felt pessimistic or discouraged about his/her future } \\
\text { this past week? Can your relative see his/her situation improving? Can } \\
\text { your relative be reassured by others that things will be okay or that } \\
\text { his/her situation will improve? }\end{array}$ & $\begin{array}{l}\text { Is the person discouraged } \\
\text { or expressing pessimistic } \\
\text { or negative thoughts? }\end{array}$ & $\begin{array}{ll}\text { - } & \text { No negativity } \\
\text { - } & \text { Some negativity } \\
\text { - } & \text { A lot of negativity } \\
\text { - } & \text { Unable to evaluate }\end{array}$ \\
\hline
\end{tabular}

${ }^{\mathrm{a} C S D D}$ : Cornell Scale for Depression in Dementia.

${ }^{b}$ mCSDD4-MA: 4-item Cornell Scale for Depression in Dementia for Momentary Assessment.

${ }^{\mathrm{c}} \mathrm{N} / \mathrm{A}$ : not applicable.

${ }^{\mathrm{d}}$ Italicization indicates the words that were taken from the original tool and used directly in the 4-item Cornell Scale for Depression in Dementia for Momentary Assessment tool. 
Textbox 1. Developed self-reported items in the modified 4-item Cornell Scale for Depression in Dementia for Momentary Assessment tool for people with advanced dementia.

4-Item Cornell Scale for Depression in Dementia for Momentary Assessment Tool Patient-Reported Items and Scoring

- $\quad$ Self-reported sadness

- $\quad$ Are you feeling sad?

- Yes

- No

- Unable to evaluate

- $\quad$ Self-reported anxiety

- $\quad$ Are you feeling worried?

- Yes

- No

- Unable to evaluate

Observational items were scored on a 3-point scale where $n o=0$, some $=1$, and a lot $=2$. Originally, the CSDD-4 tool included none $=0, \quad$ mild/intermittent $=1$, and extreme $=2 \quad[11,13]$. Patient-reported items were scored as yes or no. For the self-report items, raters were encouraged to take time to engage with the participants with the intention of asking these items naturally. Where there would be any inclination toward a yes (ie, including maybe), yes would be chosen, whereas only a clear no was scored as a no in the tool. If participants were asleep or receiving care, raters would select unable to evaluate for each item. A total score was generated for items that formed part of the CSDD-4 tool. As the other items were novel in the tool, it was not yet known if these could be included in the total score.

\section{Provisional Diagnostic Criteria for Depression of Alzheimer's Disease}

The Provisional Diagnostic Criteria for Depression of Alzheimer's Disease (PDC-dAD) [4] was used to diagnose clinical depression based on the presence of at least three core symptoms (one of which must be depressed mood or decreased positive affect) within a 2 -week period that represented a change from previous functioning. These criteria have been validated in people with dementia. Overall, the findings support the criterion, content, and convergent validity of the PDC-dAD [36]. Specifically, the PDC-dAD has shown greater sensitivity to depression in dementia compared with other common clinical interviews, such as the Diagnostic and Statistical Manual of Mental Disorders [3,4,37]. The PDC-dAD was also able to discriminate group differences on the Hamilton Depression Rating Scale and the Neuropsychiatric Inventory (NPI), highlighting its convergent validity [36].

\section{The Improved Clinical Global Impressions Scale}

The Improved Clinical Global Impressions (iCGI) scale [38] comprises the 7-item (normal, not ill at all=1 to among the most extremely ill patients=7) Severity subscale and the 13-item (ideal improvement $=6$ to maximum deterioration=-6) Improvement subscale. The iCGI has demonstrated good to excellent interrater reliability (ie, intraclass correlations [ICCs] ranging from 0.62-0.94) and large effect sizes in measuring sensitivity to change (ie, Cohen $d$ values of 0.76-1.02) and has been validated in people with depression $[38,39]$.

\section{NPI Dysphoria Subscale}

The NPI dysphoria item was rated on a 3-item severity scale ( mild $=1$, moderate $=2$, and marked $=3$ ) and a 4-item frequency scale (occasionally $=1$, often $=2$, frequently $=3$, very frequently $=4$ ). The dysphoria subscale has been shown to correlate significantly with the Hamilton Depression Rating Scale and has shown strength as a stand-alone measure, demonstrating good interrater reliability and strong convergent validity with the CSDD-19 [40]. ICCs by items ranged from 0.54-0.89 [40,41]. The NPI has also been validated in people with dementia and was chosen as it was familiar to clinical staff $[42,43]$.

\section{Procedures}

At baseline and at 6 weeks, diagnostic assessments for depression were completed by a geriatric psychiatrist using the PDC-dAD scale [4], the iCGI scale [38], and the NPI dysphoria subscale [42]. Participants were observed by trained research staff for up to four times a day, 7 days a week, over a 6-week period, and their symptoms were recorded using the mCSDD4-MA tool on a mobile phone.

Before the commencement of data collection, observer training for the research staff was undertaken. This consisted of guidance related to detecting and interpreting depressive symptoms based on affective and behavioral cues and explaining the technical aspects of the mCSDD4-MA tool [20]. Preliminary trial ratings were completed and discussed with raters to ensure that the tool was being used correctly and to improve rater consistency. Four raters recorded depressive symptoms exhibited by participants in pairs on a rotating basis, four times a day (ie, 10-11 AM, 1-2 PM, 4-5 PM, and 7-8 PM) using the tool. The pairs of raters responsible for observing participants on any given day observed all of the enrolled participants within the 1-hour observation period at each timeslot. The raters were blinded to the depression 
diagnosis for all participants and their co-rater's depressive symptom ratings.

\section{Statistical Analyses}

A large number of observations (approximately 4 observations $\times 12$ participants $\times 2$ raters $\times$ approximately 7 days $\times$ approximately 6 weeks) were undertaken. Descriptive analyses were completed for the demographic and EMA data, including feasibility data (ie, completion rates, unable to evaluate ratings, and observations of participant acceptability). Completion rates included unable to evaluate ratings as completed observations, whereas missing data were defined as the absence of a reported observation during the assigned timeslot. Having reported a participant as unable to be evaluated was thus not classified as a missed observation and instead indicated feasibility data related to observing participants.

Separate cross-classified mixed effects ordinal logistic regression models (ie, cumulative link mixed models) were fit for each item of the mCSDD4-MA tool as the dependent variable, with day and hour variables as fixed effects, participant and observer variables as crossed random effects, and a fixed interaction between day and participant [44]. These models provided estimates of the variances of the random intercepts for participants and observers. The ICC values were generated from these variances [45]. A higher participant ICC would suggest that the variability of the random intercepts was accounted for largely by mood changes in the participants and less because of the sources of error related to the observers [44].

Polychoric correlations $(r)$ were generated to examine the interrater reliability between pairs of raters for each item [46]. Krippendorff $\alpha$ values were also generated for each item, given that they evaluate the agreement between multiple raters and multiple time periods and have shown to handle missing data well [47]. Consistent with previous literature, a value of $\alpha>.67$ is used to denote moderate agreement and $\alpha>.80$ for excellent agreement [48]. Pairwise polychoric correlations and the level of incongruency between observers and self-reports were generated to examine the relationship between groups of ratings.

To establish construct validity, participants were categorized into clinically depressed and nondepressed groups at baseline, as determined by the PDC-dAD. Total scores for each mCSDD4-MA item and a total score for the baseline week were generated by averaging each participant's first week data. Wilcoxon rank-sum tests between the 2 groups were run for each item and for the total score, and Cohen $d$ effect sizes were generated for each item.

Additional ordinal logistic regression models were fit (ie, cumulative link models) to establish if EMA data could predict clinical depression at the start and end of the study. These models were generated for each item individually, with the mCSDD-4MA symptom ratings and the interaction of the mCSDD-4MA symptom ratings and day inserted as fixed effects. A model was also generated using the total score at each time point and the interaction of the total score and day as fixed effects. The presence of clinical depression on the PDC-dAD admission and discharge assessments was the dependent variable for all models. This process was repeated for the iCGI admission and discharge as dependent variables. All statistical tests were analyzed with $P>.05$.

\section{Results}

\section{Feasibility and Completion Rates}

The demographic characteristics of the participants are presented in Table 2. A total of 1923 observations were completed. This represented a 55.06\% (1923/3496) completion rate across the 6-month study, based on 2 raters present at each timeslot, 7 days a week. When excluding weekends and the 7 PM timeslot, the completion rate was $92.01 \%$ (1923/2090), with 2 raters present. If at least one rater was present at any point in time, the rate was $66.01 \%$ (1923/2913) for 7 days a week. Once weekends and evenings were excluded, the completion rate increased to $98.01 \%$ (1923/1962), with at least one rater present. Across the day, 29.02\% (558/1923), 31.98\% (615/1923), 30.99\% $(596 / 1923)$, and $8.01 \%(154 / 1923)$ of all reported observations occurred at the 10 AM, 1 PM, 4 PM, and 7 PM timeslots, respectively. The majority of the data were skewed toward reporting the absence of symptoms. The most to least frequent items reported were lack of interest, sadness, anxiety, irritability, and negativity (Multimedia Appendices 1 and 2).

Overall, the rating unable to evaluate was selected at $26.99 \%$ $(519 / 1923)$ of the observations, $41.03 \%(789 / 1923)$ of the self-reported sadness, and $43.52 \% \quad(837 / 1923)$ of the self-reported anxiety items. The 7 PM-8 PM timeslot resulted in the greatest inability to evaluate participants where more than half of all observations $(83 / 154,53.9 \%)$ and self-reports during this time were reported as unable to be evaluated, usually because the participants were already asleep. The 10 AM-11 AM timeslot was next, where $32.9 \%$ (184/558) of each observational rating could not be evaluated during that time (Multimedia Appendix 3). Overall, participants' experiences with being assessed were positive, and many expressed appreciations for visits from the observers.

On the basis of the random intercept variances of the participant and the observer, the participant ICCs ranged from 0.13-0.48 for the different symptoms, whereas the observer ICC ranged from $0.00-0.06$. Thus, the variability in random intercepts was accounted for primarily by the participants, rather than the rater for most symptoms (Multimedia Appendix 4). 
Table 2. Demographic characteristics of patient participants $(\mathrm{N}=12)$.

\begin{tabular}{|c|c|c|c|}
\hline Characteristics & Total sample $(\mathrm{N}=12)$ & Depressive symptoms $(n=4)^{\mathrm{a}}$ & No depressive symptoms $(\mathrm{n}=8)$ \\
\hline Age (years), mean (SD) & $77.4(8.2)$ & $81.3(9.3)$ & $75.5(6.7)$ \\
\hline \multicolumn{4}{|l|}{ Dementia type, n (\%) } \\
\hline Alzheimer & $9(75)$ & $3(75)$ & $6(75)$ \\
\hline Vascular & $2(17)$ & $0(0)$ & $2(25)$ \\
\hline Parkinson dementia & $1(8)$ & $1(25)$ & $0(0)$ \\
\hline $\mathrm{MMSE}^{\mathrm{b}}$, median (IQR) & $0(2.5)$ & $0(4.8)$ & $0(2.5)$ \\
\hline Sex (female), n (\%) & $5(42)$ & $3(75)$ & $2(25)$ \\
\hline Duration in study (days), mean (SD) & $38.1(8.3)$ & $35.5(11.9)$ & $39.4(6.4)$ \\
\hline NPI $^{c}$ admission, mean (SD) & $42.3(22.3)$ & $51.5(13.6)$ & $37.6(25.1)$ \\
\hline NPI dysphoria admission & $2.83(4.7)$ & $8.50(4.1)$ & $0(0)$ \\
\hline NPI discharge, mean (SD) & $18.9(15.3)$ & $24.8(6.6)$ & $16.0(18.0)$ \\
\hline NPI dysphoria discharge & $2.00(3.6)$ & $4.00(4.6)$ & $1.00(2.8)$ \\
\hline PDC-dAD ${ }^{\mathrm{d}}$ depressed admission, $\mathrm{n}(\%)$ & $2(17)$ & $2(50)$ & $0(0)$ \\
\hline PDC-dAD depressed discharge, $\mathrm{n}(\%)$ & $1(8.3)$ & $1(25)$ & $0(0)$ \\
\hline iCGI ${ }^{\mathrm{e}}$ admission, mean (SD) & $2.92(1.4)$ & $4.25(1.7)$ & $2.25(0.7)$ \\
\hline iCGI discharge, mean (SD) & $2.08(1.2)$ & $2.75(1.3)$ & $1.75(1.0)$ \\
\hline iCGI improvement score, mean (SD) & $1.00(2.0)$ & $1.50(3.1)$ & $0.75(1.4)$ \\
\hline
\end{tabular}

${ }^{a}$ Defined by a Neuropsychiatric Inventory cutoff $>4$.

${ }^{\mathrm{b}}$ MMSE: Mini-Mental State Examination.

${ }^{c}$ NPI: Neuropsychiatric Inventory.

${ }^{d}$ PDC-dAD: Provisional Diagnostic Criteria for Depression of Alzheimer's Disease.

eiCGI: Improved Clinical Global Impressions.

\section{Interrater Reliability}

For all pairs of raters, interrater reliability ranged from 0.67-0.92 for sadness, 0.57-0.83 for anxiety, 0.41-0.90 for irritability, -0.07 to 0.82 for negativity, and $0.24-0.79$ for lack of interest (Table 3). These analyses identified that the fourth rater was consistently less reliable, given the differences in their scores.
Thus, separate reliability analyses were conducted using all raters and only raters 1-3.

Krippendorff $\alpha$ values across all raters were generated and showed moderate reliability for sadness $(\alpha=.74)$ and irritability $(\alpha=.67)$ but lower reliability for negativity $(\alpha=.62)$, anxiety $(\alpha=.61)$, and lack of interest $(\alpha=.45)$. Once the fourth rater was excluded, the $\alpha$ values increased, but the trends remained the same (Table 4). 
Table 3. Polychoric correlations ( $r$ ) of the observational data comparing pairs of the 4 researchers for each of the items.

\begin{tabular}{|c|c|c|c|}
\hline Raters & 1 & 2 & 3 \\
\hline \multicolumn{4}{|c|}{ Sadness } \\
\hline 2 & 0.91 & $-^{\mathrm{a}}$ & - \\
\hline 3 & 0.86 & 0.67 & - \\
\hline 4 & 0.75 & 0.59 & 0.57 \\
\hline \multicolumn{4}{|c|}{ Irritability } \\
\hline 2 & 0.87 & - & - \\
\hline 3 & 0.90 & 0.72 & - \\
\hline 4 & 0.66 & 0.50 & 0.41 \\
\hline \multicolumn{4}{|c|}{ Negativity } \\
\hline 2 & 0.75 & - & - \\
\hline 3 & 0.82 & 0.62 & - \\
\hline 4 & 0.28 & -0.07 & 0.71 \\
\hline \multicolumn{4}{|c|}{ Anxiety } \\
\hline 2 & 0.82 & - & - \\
\hline 3 & 0.83 & 0.71 & - \\
\hline 4 & 0.75 & 0.59 & 0.57 \\
\hline \multicolumn{4}{|c|}{ Lack of interest } \\
\hline 2 & 0.69 & - & - \\
\hline 3 & 0.79 & 0.50 & - \\
\hline 4 & 0.34 & 0.27 & 0.24 \\
\hline
\end{tabular}

${ }^{\mathrm{a}} \mathrm{N} / \mathrm{A}$ : not applicable.

Table 4. Krippendorff $\alpha$ values for ecological momentary assessment item data by research staff.

\begin{tabular}{ll}
\hline Item & Krippendorff $\alpha$ \\
\hline Raters 1-4 & .74 \\
Sadness & .61 \\
Anxiety & .67 \\
Irritability & .45 \\
Lack of interest & .62 \\
Negativity & \\
Raters 1-3 & .78 \\
Sadness & .65 \\
Anxiety & .77 \\
Irritability & .54 \\
Lack of interest & .62 \\
Negativity &
\end{tabular}

\section{Concordance Between Observational and Self-reported} Items

Patient-self-reported symptoms were moderately correlated with observer-rated sadness $(r=0.68)$ and anxiety $(r=0.57)$. When participants reported feeling sad or anxious, raters would observe sadness $88.1 \%(730 / 829)$ of the time and would observe anxiety $78.9 \%(601 / 761)$ of the time. When raters reported observed depressive symptoms, participants would confirm feeling sad in $90.97 \%(968 / 1064)$ of the cases and would confirm feeling worried in $93.83 \%(1081 / 1152)$ of the cases. Overall, $72.95 \%$ (1403/1923) of the ratings showed agreement between observers and self-reports of sadness and anxiety (Multimedia Appendix 5). 


\section{Construct Validity}

Observer-rated sadness, anxiety, and total symptom score in the first week of assessment were significantly associated with the presence of clinical depression at baseline, as determined by the PDC-dAD (Wilcoxon-rank sum, W=20, $P=.04$, Cohen $d=1.00$ for sadness; $\mathrm{W}=20, P=.04$, Cohen $d=0.49$ for anxiety; and $\mathrm{W}=20, P=.03$, Cohen $d=1.00$ for the total score).

Observational and self-reported measures of sadness and anxiety over the course of the study were associated with clinical depression diagnosis over time, as determined by the PDC-dAD at baseline and at 6 weeks. Scoring at least some (vs no) observational sadness and anxiety increased the log odds of clinical depression diagnosis by 2.74 and 1.51 , respectively. Likewise, scoring a lot (vs no) of observational sadness and anxiety increased the log odds of clinical depression diagnosis by 5.37 and 3.13, respectively. Finally, answering yes (vs no) on the sadness and anxiety self-reports increased the log odds of clinical depression diagnosis by 2.20 and 2.58 , respectively (Table 5).

Table 5. Association between items in the modified 4-item Cornell Scale for Depression in Dementia for Momentary Assessment tool and clinical depression, as determined by the Provisional Diagnostic Criteria for Depression and Dementia, over the course of the study.

\begin{tabular}{|c|c|c|c|}
\hline Items and item score & Estimate (SE) & $P$ value & $95 \% \mathrm{CI}$ \\
\hline \multicolumn{4}{|l|}{ Sadness } \\
\hline 2 & $2.74(0.62)$ & $<.001^{\mathrm{a}}$ & 1.52 to 3.95 \\
\hline 3 & $5.37(0.73)$ & $<.001^{\mathrm{a}}$ & 3.93 to 6.80 \\
\hline \multicolumn{4}{|l|}{ Anxiety } \\
\hline 2 & $1.51(0.32)$ & $<.001^{\mathrm{a}}$ & 0.87 to 2.15 \\
\hline 3 & $3.13(0.58)$ & $<.001^{\mathrm{a}}$ & 2.00 to 4.26 \\
\hline \multicolumn{4}{|l|}{ Irritability } \\
\hline 2 & $0.44(0.62)$ & .47 & -0.77 to 1.67 \\
\hline 3 & $0.61(0.79)$ & .44 & -0.95 to 2.17 \\
\hline \multicolumn{4}{|l|}{ Lack of interest } \\
\hline 2 & $-0.46(0.54)$ & .40 & -1.52 to 0.60 \\
\hline 3 & $0.74(0.85)$ & .86 & -0.94 to 2.42 \\
\hline \multicolumn{4}{|l|}{ Negativity } \\
\hline 2 & $0.74(0.58)$ & .20 & -0.39 to 1.88 \\
\hline 3 & $1.61(1.93)$ & .40 & -2.16 to 5.40 \\
\hline \multicolumn{4}{|l|}{ Self-reported sadness } \\
\hline 2 & $2.20(0.47)$ & $<.001^{\mathrm{a}}$ & 1.07 to 2.94 \\
\hline \multicolumn{4}{|l|}{ Self-reported anxiety } \\
\hline 2 & $2.58(0.51)$ & $<.001^{\mathrm{a}}$ & 1.59 to 3.58 \\
\hline
\end{tabular}

${ }^{\mathrm{a}} P=.04$.

In addition to sadness, anxiety, and self-reported anxiety, negativity over the course of the study also predicted depressive symptom severity, as measured by the iCGI Severity scale. Scoring a lot of sadness and anxiety relative to no increased the $\log$ odds of severe depressive symptoms by 4.49 and 4.81 , respectively. Scoring some anxiety and negativity compared with no increased the log odds of severe depressive symptoms by 1.93 and 1.13 , respectively. Finally, answering yes compared with no for the anxiety self-report decreased the log odds of severe depressive symptoms by 0.63 (Multimedia Appendix 6).

The total CSDD-4 score generated at each observation point did not predict clinical depression diagnosis or depressive symptoms as determined by the PDC-dAD or iCGI over the course of the study.

\section{Discussion}

\section{Principal Findings}

Our study evaluated the performance of the mCSDD4-MA tool for assessing depression in people with advanced dementia. EMA ratings of depressive symptoms show potential for identifying clinical depression and can contribute to a wider understanding of depression assessment in this population. EMA approach showed preliminary feasibility, and the items demonstrated moderate reliability, with the exception of lack of interest. Moderate correlations were observed between the observational and patient-reported items. In addition, the tool showed construct validity across several items and for the total score and promising predictive validity for several items. 
The mCSDD4-MA tool was feasible and acceptable to the participants, with the participants enjoying engagement by the research staff. Overall, 7 PM-8 PM and 10 AM-11 AM timeslots accounted for the lowest proportion of observations based on both observer completion rates and their ability to observe participants. In terms of observing participants, these times may occur when participants are sleeping or receiving personal care. From a feasibility perspective, it may be appropriate to cut down to 2 observations per day in the afternoon. However, the next steps require comparing the sensitivity of the tool when observing participants two times versus four times a day to conclude if two observations are sufficient.

Capturing observational ratings of depressive symptoms repeatedly in real time was found to be a reliable method for assessment. Item-level analyses demonstrated that sadness and irritability were the most reliable and that anxiety and negativity were less reliable. This is consistent with previous research in which observers who repeatedly rated effect in people with dementia in real time found high interrater reliabilities for sadness and irritability [20]. Sadness and irritability may be easily recognizable because of their intensity and are thought to be biologically hard-wired emotions [20,49]. Ratings of anxiety were less reliable between raters, which may be related to their high heterogeneity in the presence of emotional disorders [20].

Although four out of five items demonstrated good psychometric properties, lack of interest displayed clear psychometric problems for which there are several possible explanations. These relate to the time taken to assess the item, the definition of the item, and the overlap of lack of interest with apathy. First, it is possible that insufficient time was spent observing participants to properly assess their degree of interest. The evaluation of interest requires both the presence of engaging activities to stimulate interest as well as the time to observe whether an individual is deriving any enjoyment from the activity [20]. Even in a well-resourced inpatient unit, there may still be moments throughout the day of low activity or understimulation for participants. Second, the adaptation of the lack of interest item for real-time assessment was: "Is the person showing enjoyment or pleasure in what is going on around them?" with options, "No lack of interest," "Some lack of interest," and "Lacking a lot of interest." Studies have shown that although pleasure and interest are highly correlated, there is heterogeneity in the definition of anhedonia [50]. As pleasure and enjoyment were included in the question, and interest was used in the response, this may have affected the understanding of the item. Finally, symptom overlap with apathy (ie, loss of interest and motivation, fatigue, and low social engagement) may have confounded the item [51]. Overall, there is a need to develop a more reliable lack of interest item for real-time assessment. This would require modifications such as wording the item to be more closely related to the concept of anhedonia and more distinct from apathy, recommending longer observation periods for evaluating the presence of symptoms, and improving rater training [20,52].

Using EMA to measure depressive symptoms in advanced dementia also shows construct and predictive validity, as demonstrated by its association with depression at baseline and over time. Our analyses confirmed the validity of several items, including observed sad and anxious affect, which have been previously reported to predict and correlate with depression and depressive symptoms in people with dementia $[19,20]$. In this study, we were also able to demonstrate a relationship between patient-reported symptoms in a population with advanced dementia and clinical depression and symptoms. This is a unique finding, as self-reporting is not typically included in observer-rated depression assessments. This lends some support to the inclusion of patient self-reports, in keeping with patient-centered care approaches. Negativity was also shown to be associated with depressive symptoms; however, the rating of negativity was contingent on the participants' ability to communicate negative cognitions. Although negativity is a highly specific depressive symptom in advanced dementia, it has poor sensitivity given its low frequency. Overall, several items in the mCSDD4-MA tool demonstrated a promising ability to detect clinically significant depression and depressive symptoms.

Discrepancies between informant and patient-reported symptoms are well documented in the literature and were found in this study, illustrating the importance of collecting both types of reports. Low patient-proxy agreement in mood can be attributed to subjectivity in observing these items and raters attributing depressive symptoms to dementia or vice versa $[10,53,54]$. In this study, the majority of ratings (1403/1923, 72.95\%) completed by participants and observers were concordant. In $57 \%(12 / 21)$ and $78 \%(21 / 27)$ of the discordant ratings, the participants self-reported the presence of sad and anxious mood, respectively, whereas observers rated the symptoms as absent. This differs from the literature in which people with dementia have reported fewer symptoms than their informants, although some studies have shown similar results [7,8]. Again, this underscores the importance of including patient-reported ratings, although it is important to ensure the reliability of these self-reports. In this study, the severity of cognitive impairment may have affected the reliability of patient-reported outcomes. Some participants agreed to feeling sad or anxious, despite not showing any outward sign of negative affect, leading the observers to doubt whether the participants had understood the question. Thus, there is a need to improve the reliability of self-reports, which could be done by combining some neutral and positively worded questions, in addition to the questions about symptoms to ascertain the consistency of the responses [35].

This study had several limitations. As this was a pilot study, the between-person sample size affected the power and generalizability of the results to a larger population of people with advanced dementia. However, we aimed to compensate for this by achieving a large within-person sample size. In addition, although intensive longitudinal designs are limited in their generalizability to other individuals, they are strengthened by their ability to generalize across situations within individuals [32]. Although certain patient-related (ie, cognitive impairment and level of awareness) and observer-related (ie, quality of training and internal mood states) factors can have an impact on the interpretation of mood, our study did not specifically examine these effects on depression ratings. Future studies can 
address the psychometric issues with the assessment of interest in people with dementia in real time and develop EMA protocols to improve the overall psychometric properties of the tool. Given the previous findings on caregiver biases, it is important to note that research staff ratings may differ from caregiver ratings, which may limit the generalizability of these findings [6,7]. Therefore, future studies should also examine the performance across different categories of observers.

\section{Conclusions}

A modified CSDD4-MA tool for momentary assessment of depression in people with advanced dementia is feasible and has moderate reliability and validity. Repeated and real-time assessment of mood in these individuals holds promise to monitor depressive symptoms and clinical depression.

\section{Acknowledgments}

This work was generously funded by the Walter \& Maria Schroeder Institute for Brain Innovation and Recovery. The authors would also like to acknowledge Steven Stewart for his helpful contributions to statistical analyses.

\section{Authors' Contributions}

IN wrote the manuscript with support and supervision from AI, RG, and BF. IN, TA, and HQ collected data. TB contributed to statistical analyses and interpretation.

\section{Conflicts of Interest}

AI has received research grants from the Alzheimer Association, Canadian Institutes for Health Research, AGE-WELL, and the Centre for Aging and Brain Health Innovation. She is on the scientific advisory panel for Winterlight LLC. The other authors have no conflicts of interest or financial disclosures.

\section{Multimedia Appendix 1}

Frequency of research staff observations for the observational 4-item Cornell Scale for Depression in Dementia for Momentary Assessment items.

[PNG File, 45 KB-Multimedia Appendix 1]

\section{Multimedia Appendix 2}

Frequency of the self-reported 4-item Cornell Scale for Depression in Dementia for Momentary Assessment items. [PNG File, 35 KB-Multimedia Appendix 2]

\section{Multimedia Appendix 3}

Percentage of data (\%) that was rated as unable to be evaluated at each observation period.

[DOCX File, 13 KB-Multimedia Appendix 3]

\section{Multimedia Appendix 4}

Ratios of variance components of the participant and observer variables in the 4-item Cornell Scale for Depression in Dementia for Momentary Assessment items.

[DOCX File, 14 KB-Multimedia Appendix 4]

\section{Multimedia Appendix 5}

The level of congruence between observational sadness and anxiety and self-reported sadness and anxiety. [PNG File, 50 KB-Multimedia Appendix 5]

\section{Multimedia Appendix 6}

Association between items in the 4-item Cornell Scale for Depression in Dementia for Momentary Assessment tool and clinical depressive symptoms, as measured by the Improved Clinical Global Impressions scale over the course of the study.

[DOCX File, 15 KB-Multimedia Appendix 6]

\section{References}

1. Engedal K, Barca ML, Laks J, Selbaek G. Depression in Alzheimer's disease: specificity of depressive symptoms using three different clinical criteria. Int J Geriatr Psychiatry 2011 Sep 07;26(9):944-951. [doi: 10.1002/gps.2631] [Medline: 21845597] 
2. Starkstein SE, Jorge R, Mizrahi R, Robinson RG. The construct of minor and major depression in Alzheimer's disease. Am J Psychiatry 2005 Nov;162(11):2086-2093. [doi: 10.1176/appi.ajp.162.11.2086]

3. Goodarzi ZS, Mele BS, Roberts DJ, Holroyd-Leduc J. Depression case finding in individuals with dementia: a systematic review and meta-analysis. J Am Geriatr Soc 2017 May 02;65(5):937-948. [doi: 10.1111/jgs.14713] [Medline: 28152174]

4. Olin JT, Schneider LS, Katz IR, Meyers BS, Alexopoulos GS, Breitner JC, et al. Provisional diagnostic criteria for depression of Alzheimer disease. Am J Geriatr Psychiatry 2002 Mar;10(2):125-128. [doi: 10.1097/00019442-200203000-00003]

5. Starkstein SE, Mizrahi R, Power BD. Depression in Alzheimer's disease: phenomenology, clinical correlates and treatment. Int Rev Psychiatry 2008 Aug 11;20(4):382-388. [doi: 10.1080/09540260802094480] [Medline: 18925487]

6. Snow A, Kunik M, Molinari V, Orengo CA, Doody R, Graham DP, et al. Accuracy of self-reported depression in persons with dementia. J Am Geriatr Soc 2005 Mar;53(3):389-396. [doi: 10.1111/j.1532-5415.2005.53154.x] [Medline: 15743279]

7. Chemerinski E, Petracca G, Sabe L, Kremer J, Starkstein SE. The specificity of depressive symptoms in patients with Alzheimer's disease. Am J Psychiatry 2001 Jan;158(1):68-72. [doi: 10.1176/appi.ajp.158.1.68] [Medline: 11136635]

8. Teri L, Wagner AW. Assessment of depression in patients with Alzheimer's disease: concordance among informants. Psychol Aging 1991;6(2):280-285. [doi: 10.1037/0882-7974.6.2.280]

9. Shiffman S, Stone AA, Hufford MR. Ecological momentary assessment. Annu Rev Clin Psychol 2008 Apr;4(1):1-32. [doi: 10.1146/annurev.clinpsy.3.022806.091415] [Medline: 18509902 ]

10. Towsley G, Neradilek MB, Snow AL, Ersek M. Evaluating the Cornell scale for depression in dementia as a proxy measure in nursing home residents with and without dementia. Aging Ment Health 2012 Sep;16(7):892-901 [FREE Full text] [doi: 10.1080/13607863.2012.667785] [Medline: 22486638]

11. Alexopoulos GS, Abrams RC, Young RC, Shamoian CA. Cornell scale for depression in dementia. Biol Psychiatry 1988 Feb;23(3):271-284. [doi: 10.1016/0006-3223(88)90038-8]

12. Jeon Y, Li Z, Low L, Chenoweth L, O'Connor D, Beattie E, et al. The clinical utility of the Cornell Scale for Depression in Dementia as a routine assessment in nursing homes. Am J Geriatr Psychiatry 2015 Aug;23(8):784-793. [doi: 10.1016/j.jagp.2014.08.013] [Medline: 25256214]

13. Jeon Y, Liu Z, Li Z, Low L, Chenoweth L, O'Connor D, et al. Development and validation of a short version of the Cornell Scale for Depression in Dementia for screening residents in nursing homes. Am J Geriatr Psychiatry 2016 Nov;24(11):1007-1016. [doi: 10.1016/j.jagp.2016.05.012] [Medline: 27538349]

14. Mehta KM, Yaffe K, Langa KM, Sands L, Whooley MA, Covinsky KE. Additive effects of cognitive function and depressive symptoms on mortality in elderly community-living adults. J Gerontol A Biol Sci Med Sci 2003 May 01;58(5):461-467 [FREE Full text] [doi: 10.1093/gerona/58.5.m461] [Medline: 12730257]

15. Enache D, Winblad B, Aarsland D. Depression in dementia : epidemiology, mechanisms, and treatment. Curr Opin Psychiatry 2011;24(6):461-472. [doi: 10.1097/yco.0b013e32834bb9d4]

16. Moore RC, Depp CA, Wetherell JL, Lenze EJ. Ecological momentary assessment versus standard assessment instruments for measuring mindfulness, depressed mood, and anxiety among older adults. J Psychiatr Res 2016 Apr;75:116-123. [doi: 10.1016/j.jpsychires.2016.01.011] [Medline: 26851494]

17. Kim H, Lee S, Lee S, Hong S, Kang H, Kim N. Depression prediction by using ecological momentary assessment, actiwatch data, and machine learning: observational study on older adults living alone. JMIR Mhealth Uhealth 2019 Oct 16;7(10):e14149 [FREE Full text] [doi: 10.2196/14149] [Medline: 31621642]

18. Kim H, Kim S, Kong S, Jeong Y, Kim H, Kim N. Possible application of ecological momentary assessment to older adults' daily depressive mood: integrative literature review. JMIR Ment Health 2020 Jun 02;7(6):e13247 [FREE Full text] [doi: 10.2196/13247] [Medline: 32484442]

19. Kolanowski A, Hoffman L, Hofer SM. Concordance of self-report and informant assessment of emotional well-being in nursing home residents with dementia. J Gerontol B Psychol Sci Soc Sci 2007 Jan 01;62(1):20-27. [doi: 10.1093/geronb/62.1.p20] [Medline: 17284553 ]

20. Lawton MP, Van Haitsma K, Klapper J. Observed affect in nursing home residents with Alzheimer's disease. J Gerontol B Psychol Sci Soc Sci 1996 Jan 01;51(1):3-14. [doi: 10.1093/geronb/51b.1.p3] [Medline: 8548515]

21. de Boer B, Beerens H, Zwakhalen S, Tan F, Hamers J, Verbeek H. Daily lives of residents with dementia in nursing homes: development of the Maastricht electronic daily life observation tool. Int Psychogeriatr 2016 Mar 23;28(8):1333-1343. [doi: $10.1017 / \mathrm{s} 1041610216000478]$

22. Rullier L, Atzeni T, Husky M, Bouisson J, Dartigues J, Swendsen J, et al. Daily life functioning of community-dwelling elderly couples: an investigation of the feasibility and validity of Ecological Momentary Assessment. Int J Methods Psychiatr Res 2014 Jun;23(2):208-216. [doi: 10.1002/mpr.1425] [Medline: 24375556]

23. Junge S, Gellert P, O'Sullivan JL, Möller S, Voigt-Antons J, Kuhlmey A, et al. Quality of life in people with dementia living in nursing homes: validation of an eight-item version of the QUALIDEM for intensive longitudinal assessment. Qual Life Res 2020 Jun 18;29(6):1721-1730 [FREE Full text] [doi: 10.1007/s11136-020-02418-4] [Medline: 31955375]

24. Folstein MF, Robins LN, Helzer JE. The mini-mental state examination. Arch Gen Psychiatry 1983 Jul 01;40(7):812. [doi: 10.1001/archpsyc.1983.01790060110016] [Medline: 6860082]

25. Cain AE, Depp CA, Jeste DV. Ecological momentary assessment in aging research: a critical review. J Psychiatr Res 2009 Jul;43(11):987-996. [doi: 10.1016/j.jpsychires.2009.01.014] [Medline: 19272611] 
26. Paterson C, Jones M, Rattray J, Lauder W, Nabi G. What is the mechanism effect that links social support to coping and psychological outcome within individuals affected by prostate cancer? Real time data collection using mobile technology. Eur J Oncol Nurs 2016 Apr;21:126-133. [doi: 10.1016/j.ejon.2015.09.002] [Medline: 26440544]

27. Astivia OL, Gadermann A, Guhn M. The relationship between statistical power and predictor distribution in multilevel logistic regression: a simulation-based approach. BMC Med Res Methodol 2019 May 9;19(1):97. [doi:

10.1186/s12874-019-0742-8]

28. Kerkhoff D, Nussbeck FW. The influence of sample size on parameter estimates in three-level random-effects models. Front Psychol 2019 May 21;10:1067 [FREE Full text] [doi: 10.3389/fpsyg.2019.01067] [Medline: 31164847]

29. Sadikaj G, Wright A, Dunkley D, Zuroff D, Moskowitz D. Multilevel structural equation modeling for intensive longitudinal data: a practical guide for personality researchers. In: The Handbook of Personality Dynamics and Processes. Cambridge, Massachusetts, United States: Academic Press; 2021:855-885.

30. Lafit G, Adolf J, Dejonckheere E, Myin-Germeys I, Viechtbauer W, Ceulemans E. Selection of the number of participants in intensive longitudinal studies: a user-friendly Shiny App and tutorial for performing power analysis in multilevel regression models that account for temporal dependencies. Adv Methods Pract Psychol Sci 2021 Mar 23;4(1):1-24. [doi: $10.1177 / 2515245920978738]$

31. Maas CJ, Hox JJ. Sufficient sample sizes for multilevel modeling. Methodology 2005 Jan;1(3):86-92. [doi: 10.1027/1614-2241.1.3.86]

32. Conner TS, Tennen H, Fleeson W, Barrett LF. Experience sampling methods: a modern idiographic approach to personality research. Soc Personal Psychol Compass 2009 May 1;3(3):292-313 [FREE Full text] [doi: 10.1111/j.1751-9004.2009.00170.x] [Medline: 19898679 ]

33. Alexopoulos GS. Depression in the elderly. Lancet 2005 Jun;365(9475):1961-1970. [doi: 10.1016/s0140-6736(05)66665-2]

34. Gallo JJ, Rabins PV. Depression without sadness: alternative presentations of depression in late life. Am Fam Physician 1999 Sep 01;60(3):820-826 [FREE Full text] [Medline: 10498109]

35. Tappen RM, Barry C. Assessment of affect in advanced Alzheimer's disease: the Dementia Mood Picture Test. J Gerontol Nurs 1995 Mar 01;21(3):44-46. [doi: 10.3928/0098-9134-19950301-09] [Medline: 7706649]

36. Sepehry A, Lee P, Hsiung G, Beattie B, Feldman H, Jacova C. The 2002 NIMH Provisional Diagnostic Criteria for Depression of Alzheimer's Disease (PDC-dAD): gauging their validity over a decade later. J Alzheimer's Dis 2017 May 11;58(2):449-462. [doi: 10.3233/jad-161061]

37. Asmer MS, Kirkham J, Newton H, Ismail Z, Elbayoumi H, Leung RH, et al. Meta-analysis of the prevalence of Major Depressive Disorder among older adults with dementia. J Clin Psychiatry 2018 Jul 31;79(5):r11772. [doi: 10.4088/jcp.17r11772]

38. Kadouri A, Corruble E, Falissard B. The improved Clinical Global Impression Scale (iCGI): development and validation in depression. BMC Psychiatry 2007 Feb 06;7(1):7. [doi: 10.1186/1471-244x-7-7]

39. Romijn AR, Rucklidge JJ, Kuijer RG, Frampton C. A double-blind, randomized, placebo-controlled trial of Lactobacillus helveticus and Bifidobacterium longum for the symptoms of depression. Aust N Z J Psychiatry 2017 Aug 10;51(8):810-821 [FREE Full text] [doi: 10.1177/0004867416686694] [Medline: 28068788]

40. de Medeiros K, Robert P, Gauthier S, Stella F, Politis A, Leoutsakos J, et al. The Neuropsychiatric Inventory-Clinician rating scale (NPI-C): reliability and validity of a revised assessment of neuropsychiatric symptoms in dementia. Int Psychogeriatr 2010 Sep;22(6):984-994 [FREE Full text] [doi: 10.1017/S1041610210000876] [Medline: 20594384]

41. Wood S, Cummings JL, Hsu M, Barclay T, Wheatley MV, Yarema KT, et al. The use of the neuropsychiatric inventory in nursing home residents. Characterization and measurement. Am J Geriatr Psychiatry 2000 Dec;8(1):75-83. [doi: 10.1097/00019442-200002000-00010] [Medline: 10648298]

42. Cummings JL. The Neuropsychiatric Inventory: assessing psychopathology in dementia patients. Neurology 1997 May 01;48(5 Suppl 6):10-16. [doi: 10.1212/wnl.48.5 suppl 6.10s] [Medline: 9153155]

43. Cummings JL, Mega M, Gray K, Rosenberg-Thompson S, Carusi DA, Gornbein J. The Neuropsychiatric Inventory: comprehensive assessment of psychopathology in dementia. Neurology 1994 Dec 01;44(12):2308-2314. [doi: 10.1212/wnl.44.12.2308] [Medline: 7991117]

44. Bolger N, Laurenceau J. Introduction to intensive methods. In: Intensive Longitudinal Methods: An Introduction to Diary Experience Sampling Research. New York, United States: The Guilford Press; 2013:1-256.

45. Hedeker D. Multilevel models for ordinal and nominal variables. In: Leeuw J, Meijer E, editors. Handbook of Multilevel Analysis. New York: Springer; 2008:237-274.

46. Mukaka MM. Statistics corner: a guide to appropriate use of correlation coefficient in medical research. Malawi Med J 2012 Sep;24(3):69-71 [FREE Full text] [Medline: 23638278]

47. Krippendorff K. Estimating the reliability, systematic error and random error of interval data. Educ Psychol Meas 2016 Jul 02;30(1):61-70. [doi: 10.1177/001316447003000105]

48. Shelley M, Krippendorff K. Content Analysis: an introduction to its methodology. J Am Stat Assoc 1984 Mar;79(385):240. [doi: $10.2307 / 2288384]$

49. Kätsyri J, Sams M. The effect of dynamics on identifying basic emotions from synthetic and natural faces. Int J Hum Comput Stud 2008 Apr;66(4):233-242. [doi: 10.1016/j.ijhcs.2007.10.001] 
50. Rizvi SJ, Pizzagalli DA, Sproule BA, Kennedy SH. Assessing anhedonia in depression: potentials and pitfalls. Neurosci Biobehav Rev 2016 Jun;65:21-35 [FREE Full text] [doi: 10.1016/j.neubiorev.2016.03.004] [Medline: 26959336]

51. Marin RS, Firinciogullari S, Biedrzycki RC. The sources of convergence between measures of apathy and depression. J Affect Disord 1993 May;28(1):7-14. [doi: 10.1016/0165-0327(93)90072-r]

52. Landes AM, Sperry SD, Strauss ME, Geldmacher DS. Apathy in Alzheimer's disease. J Am Geriatr Soc 2001 Dec;49(12):1700-1707. [doi: 10.1046/j.1532-5415.2001.49282.x] [Medline: 11844006 ]

53. Snow AL, Cook KF, Lin P, Morgan RO, Magaziner J. Proxies and other external raters: methodological considerations. Health Serv Res 2005 Oct;40(5 Pt 2):1676-1693 [FREE Full text] [doi: 10.1111/j.1475-6773.2005.00447.x] [Medline: 16179002]

54. Lachner C, Armstrong MJ, Gruber-Baldini AL, Rezvani Z, Reich SG, Fishman PS, et al. Discordance between physician assessment and patient-reported depressive symptoms in Parkinson Disease. J Geriatr Psychiatry Neurol 2017 Jul 24;30(4):191-195. [doi: 10.1177/0891988717710335] [Medline: 28535723]

\author{
Abbreviations \\ CSDD: Cornell Scale for Depression in Dementia \\ CSDD-4: 4-item Cornell Scale for Depression in Dementia \\ EMA: ecological momentary assessment \\ ICC: intraclass correlation \\ iCGI: Improved Clinical Global Impressions \\ mCSDD4-MA: 4-item Cornell Scale for Depression in Dementia for Momentary Assessment \\ NPI: Neuropsychiatric Inventory \\ PDC-dAD: Provisional Diagnostic Criteria for Depression of Alzheimer's Disease
}

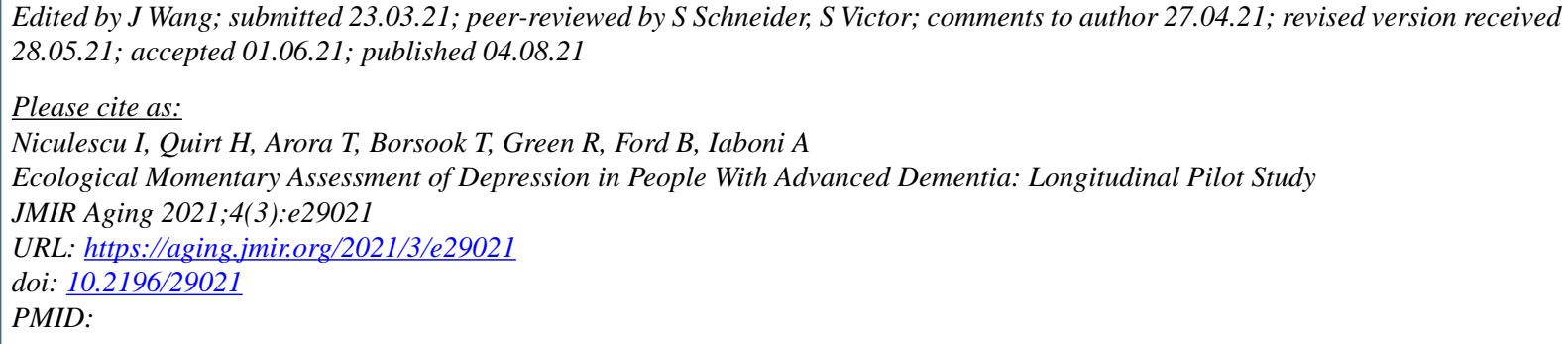

CIulia Niculescu, Hannah Quirt, Twinkle Arora, Terry Borsook, Robin Green, Brett Ford, Andrea Iaboni. Originally published in JMIR Aging (https://aging.jmir.org), 04.08.2021. This is an open-access article distributed under the terms of the Creative Commons Attribution License (https://creativecommons.org/licenses/by/4.0/), which permits unrestricted use, distribution, and reproduction in any medium, provided the original work, first published in JMIR Aging, is properly cited. The complete bibliographic information, a link to the original publication on https://aging.jmir.org, as well as this copyright and license information must be included. 